\title{
UNA VUELTA MÁS DE LA CORTE SUPREMA DE JUSTICIA DE LA NACIÓN SOBRE DESPIDO DISCRIMINATORIO
}

\section{COMENTARIO SOBRE EL CASO "VARELA"}

\author{
POR TRINIDAD BERGAMASCO ${ }^{1}$
}

Sumario: 1- Introducción. 2- Antecedentes de la CSJN: "Álvarez" y "Pellicori". 3- "Varela". Valoración de la prueba. 4.- Conclusión.

\section{I.- Introducción}

La discriminación es un flagelo que afecta severamente múltiples espacios de actuación del ser humano y no está a salvo el ámbito laboral, sino que por el contrario. Se ve con mayor frecuencia debido a la desigualdad de las partes vinculadas.

Nuestro máximo tribunal federal ha determinado a través de varias sentencias los criterios que considera fundamentales respecto de éstos casos. Recientemente, en un avance adicional, se introduce en la valoración de la prueba (cuestión ajena al recurso extraordinario federal) para aportar justicia en el precedente "Varela", que es el que motiva el análisis en el presente escrito.

\section{2- Antecedentes de la CSJN: "Álvarez" y "Pellicori"}

Recordemos que antes de la llegada de "Álvarez" a la instancia máxima, hacía tiempo que la CSJN analizaba el caso "Pellejero". Ambos encontraron sentencia el mismo día, el 7 de diciembre de 2010.

El caso "Pellejero", es el de una mujer que trabajaba en el Banco Hipotecario de Viedma y que alegaba haber sido despedida por estar casada con un dirigente gremial de los bancarios. Los autos llegaron a audiencia pública donde los ministros de la Corte indagaron sobre los hechos, para determinar si el despido podía ser calificado como discriminatorio. El Banco Hipotecario había obtenido en las dos etapas anteriores sentencia desfavorable en las cuales se le ordenaba reincorporar a María Pellejero. Desde la entidad bancaria aseguraban que Pellejero fue despedida por conceder beneficios extraordinarios a su hermano en el otorgamiento de un crédito. El abogado defensor del

1 Contadora Pública Nacional, de la U.N.C.; abogada, de la U.E. Siglo 21, Magister- en Derecho del Trabajo y Relaciones Laborales Internacionales de la Universidad Nacional Tres de Febrero; Doctora en Derecho del Trabajo, Previsión Social y Derechos Humanos, de la Universidad Nacional de San Carlos de Guatemala; actualmente cursa la Licenciatura en Gestión de RRHH en la Universidad Empresarial Siglo 21. Asesora de empresas de Córdoba en Derecho Preventivo Laboral. - Docente de la Materia Derecho Laboral y de la Seguridad Social, Facultad de Ciencias Económicas, UNC. y UCC. Expositora en numerosos congresos de Derecho del Trabajo y Seguridad Social. Publicista. 
Banco, Daniel Funes de Rioja (de un reconocido estudio de Capital Federal) reclamaba que en caso de ser desacreditada la causa de despido y aún considerando que pudiera ser discriminatorio, se estableciera la obligación de pagar una indemnización adicional, pero no la de reincorporar a un trabajador que el Banco no desea tener más en su nómina.

El Tribunal Supremo sentenció que no se configuraba la hipótesis de despido discriminatorio, por lo cual no cabía preguntarse si era aplicable o no la ley 23.592 sobre discriminación. La decisión fue adoptada por unanimidad de los siete integrantes de la Corte.

El extracto más importante y conclusivo del fallo, nos dice: "en el caso quedó demostrada la no configuración de un supuesto de discriminación susceptible de ser encuadrado en el artículo $1^{\circ}$ de la ley 23.592, determina la pérdida de sustento de las conclusiones que se extrajeron en el fallo con arreglo a ese régimen legal e impide que se proyecte aquí la doctrina establecida por esta Corte en la citada causa A.1023.XLIII "Álvarez"

Un fallo de la misma fecha es el de "Álvarez" y estimamos la Corte aguardó para tener un caso similar al de Pellejero, para poder expresar su opinión en caso de configurarse el supuesto de discriminación.

En el caso, 6 (seis) trabajadores fueron despedidos de Cencosud S.A. (nombre de fantasía: Easy) por intentar formar un sindicato, ya que estaban excluidos del convenio colectivo de trabajo, de acuerdo al encuadre que realizaba la empresa. Los actores formaron e inscribieron un sindicato: "Sindicato de Empleados Jerárquicos de Comercio", obteniendo la simple inscripción desde marzo de 2006 y pasando a integrar la comisión directiva de la institución. Al ser despedidos sin causa, luego de haber intimado como organización sindical a que se abonen diferencias salariales, los actores consideraron que el despido se correspondía con su actividad sindical y reclamaron la reincorporación y una indemnización por daños y perjuicios. Las dos instancias anteriores fueron favorables al pedido de los actores, ordenando tanto la reincorporación como la reparación económica.

La ley establece que quien discrimine será obligado a: 1- Dejar sin efecto el acto discriminatorio (volver las cosas al estado anterior, anulando el acto ilícito) o 2- Cesar en su realización (si fuera imposible volver las cosas al estado anterior). Además, deberá reparar el daño causado, lo cual es generalmente económico.

Planteó la Corte en el texto del fallo: "La cuestión federal a ser juzgada por esta Corte reside, de consiguiente, en determinar si la citada ley 23.592 es aplicable a la relación de trabajo privada, más específicamente, al distracto producido en el caso, y si la reinstalación dispuesta a la luz de su art. $1^{\circ}$ resulta compatible con los derechos que la empleadora demandada arguye sobre la base de los arts. 14, 14 bis y 16 de la Constitución Nacional".

Los jueces que se inclinaron por la apretada mayoría (4-3) fueron los Dres. Fayt, Petracchi, Maqueda y Zaffaroni.

Un extracto del fallo que marca el sentido de la protección otorgara, dice: "el acto discriminatorio ofende nada menos que el fundamento definitivo de los derechos 
humanos: la dignidad de la persona, al renegar de uno de los caracteres ínsitos de ésta: la igualdad en dignidad de todos y cada uno de los seres humanos, de la cual deriva, precisamente, el principio de igualdad y prohibición de toda discriminación, destinado a proteger en la existencia dicha igualdad en esencia, intrínseca o inherente a aquéllos".

Y como conclusión al planteo sobre la aplicación de la ley 23.592 se establece: "este orden de ideas conduce, sin hesitación, a descartar de plano la pretendida inaplicabilidad de la ley 23.592 al ámbito del derecho individual del trabajo, por tres razones, además de la que será expresada en el considerando siguiente. Primeramente, nada hay en el texto de ley ni en la finalidad que persigue que indique lo contrario. Seguidamente, "la proscripción de la discriminación no admite salvedades o ámbitos de tolerancia, que funcionarían como 'santuarios de infracciones': se reprueba en todos los casos" En tercer lugar, revista una circunstancia que hace a la norma por demás apropiada y necesaria en dicho ámbito."

Encontramos en la cita siguiente, la fundamental argumentación del voto, donde expresan que compensar en dinero la violación de los derechos humanos importa ir en contra de esos mismos derechos, lo cual es muy difícil no compartir: "El objetivo primario de las reparaciones (remedies) en materia de derechos humanos, es preciso destacarlo, debería ser la rectificación o restitución en lugar de la compensación; esta última sólo proporciona a la víctima algo equivalente a lo que fue perdido, mientras que las primeras reponen precisamente lo que le fue sacado o quitado. El intercambio de violaciones de derechos humanos con dinero, además, entraña un conflicto con el carácter inalienable de aquellos (aun cuando no puede ser descartado cuando la pérdida ha ocurrido y es irreparable).

En una postura absolutamente pragmática, nos resulta interesante ir un poco más allá mirando cómo se darán las relaciones luego de la obligación de reincorporar a un trabajador, lo cual nos resulta algo peligroso y excesivamente complicado, teniendo presente como se desarrollan las relaciones humanas en el interior de una empresa.

Nos preguntamos, que hará un empleador de una empresa pequeña si un juez le ordena la reincorporación de un trabajador y a él le afecta humanamente (aún incluso en su salud) relacionarse con esa persona que debe reincorporar? El empleador no tiene la posibilidad de renunciar y buscar otro trabajo donde esté más a gusto, con lo cual están en juego también sus derechos humanos e incluso la continuidad de la empresa. Lo planteamos simplemente como reflexión.

Por la minoría en el caso "Álvarez" y negando la posibilidad de reinstalar al trabajador en su puesto, aplicando analógicamente como indemnización adicional a los daños y perjuicios que se pueda determinar, la prevista en el art. 182 de la LCT, un año de remuneraciones, votaron nada menos que el presidente de la Corte Suprema, el Dr. Lorenzetti, la vicepresidente Dra. Higton y la Dra. Argibay.

Expresan en el voto minoritario "Que en esta línea, este Tribunal ha señalado que no se puede obligar a un empleador -contra su voluntad-a seguir manteniendo en su puesto a empleados que no gozan de la confianza que debe presidir toda relación de dependencia. También manifestó que una vez rota la relación laboral a raíz de un despido injusto se debe reconocer al trabajador el derecho a reclamar una indemnización razonablemente proporcionada al perjuicio sufrido" 
En lo que hace a la cuestión principal del fallo, que es si se aplica en el Derecho del Trabajo la ley 23.592, tanto la postura mayoritaria como la minoritaria coinciden plenamente, la norma mencionada se aplica al Derecho Laboral. Lo que difiere y por eso el voto de la minoría es una disidencia parcial, es en cómo se aplica esa norma a un Derecho tan distinto en sus bases y teniendo presentes los derechos de ambas partes, es decir tanto de los trabajadores, como de los empleadores: "En tal sentido, la legislación especifica contiene soluciones para el supuesto de despidos discriminatorios que implican una protección más intensa para el trabajador que la otorgada para el supuesto general de despido sin justa causa, pero que no llega a suprimir por completo la posibilidad de que el empleador ponga fin a la relación laboral. De esta manera, los remedios elegidos consisten, para algunos casos, en elevar considerablemente el costo que debe afrontar el empleador por la decisión de despedir sin causa al trabajador (despido motivado en el matrimonio del trabajador, artículo 182 LCT; o en el embarazo de la trabajadora, artículo 178 LCT), mientras que, en otras situaciones, la respuesta prevista por la ley es la de cancelar, por tiempo determinado, la posibilidad de despido directo sin causa (artículo 177 LCT; artículos 48 y 50 de la Ley de Asociaciones Sindicales, 23.551). En ambos supuestos, la política legislativa tiene un componente común: la presunción de que el despido es discriminatorio tiene vigencia por un plazo determinado (tres meses anteriores y seis posteriores al matrimonio -artículo 181 LCT-; por el tiempo que dure la gestación -artículo 177, tercer párrafo, LCT-; siete meses y medio anteriores y posteriores al parto -artículo 178 LCT-; por el tiempo que dure el cargo gremial, más un año -artículo 48 de la Ley de Asociaciones Sindicales-; seis meses a partir de la postulación - artículo 49 de la Ley de Asociaciones Sindicales-). Fuera de esos márgenes temporales, recupera vigencia el régimen general previsto en la LCT sobre el despido sin justa causa. (...) Ahora, ante la ausencia de previsiones legislativas expresas para otros supuestos de despidos discriminatorios, debe acudirse a una solución que, por analogía, repare debidamente los perjuicios sufridos por el trabajador. A tal fin, la aplicación de los parámetros previstos en la LCT para otros supuestos de despidos discriminatorios (por maternidad o matrimonio, artículos 177/178 y 182 respectivamente), a los que se ha hecho ya referencia, resulta - a criterio de este Tribunal- la medida más adecuada para armonizar los derechos en juego".

En un avance sobre la temática, el 15 de noviembre de 2011, el Tribunal Nacional se expidió en los autos "Pellicori" sobre la carga de la prueba, con muy buen criterio para el tema de la discriminación.

La Corte partió de un dato muy concreto, que la víctima siempre atraviesa dificultades probatorias para documentar un acto que en general, se realiza con disimulo: "Uno de los problemas de procedimiento más importantes que se plantean cuando una persona alega una discriminación en el empleo o la ocupación se refiere a que con frecuencia le corresponde la carga de la prueba del motivo discriminatorio subyacente al acto incriminado, lo que puede constituir un obstáculo insuperable a la reparación del perjuicio sufrido" (párr. 224). Lo más frecuente, acotó, "es que la discriminación sea una acción o una actividad más presunta que patente, y difícil de demostrar [...] tanto más cuanto que la información y los archivos que podrían servir de elemento de prueba están la mayor parte de las veces en manos de la persona a la que se dirige el reproche de discriminación".

La sentencia termina estableciendo una carga dinámica de la prueba: "a modo 
de conclusión, resultará suficiente, para la parte que afirma dicho motivo, con la acreditación de hechos que, prima facie evaluados, resulten idóneos para inducir su existencia, caso en el cual corresponderá al demandado a quien se reprocha la comisión del trato impugnado, la prueba de que éste tuvo como causa un motivo objetivo y razonable ajeno a toda discriminación. La evaluación de uno y otro extremo, naturalmente, es cometido propio de los jueces de la causa, a ser cumplido de conformidad con las reglas de la sana crítica".

Por último y es relevante la aclaración, no se exime al demandante de la prueba ya que debe acreditar una firme convicción de ser un sujeto que puede ser discriminado por sus características personales o su condición, ya sea sindical, política o social: "La doctrina del Tribunal, por ende, no supone la eximición de prueba a la parte que tilda de discriminatorio a un acto pues, de ser esto controvertido, pesa sobre aquélla la carga de acreditar los hechos de los que verosímilmente se siga la configuración del motivo debatido. Tampoco implica, de producirse esa convicción, una inversión de la carga probatoria ya que, ciertamente, en este supuesto, al demandado le corresponderá probar el hecho que justifique descartar el prima facie acreditado".

\section{3- "Varela". Valoración de la prueba}

En el caso "Varela", la Corte se expide el 4 de septiembre del 2018 nuevamente sobre una cuestión discriminatoria. Lo interesante de los autos es que la empresa demandada, en primera instancia, no contesta siquiera la demanda. El Juez condena a Disco a reinstalar al actor, al pago de los salarios caídos y a abonar una multa por la práctica desleal. La Cámara desestima el fallo centrando la cuestión en la Ley de Asociaciones Sindicales (como estaba planteado), y estableciendo que un trabajador no puede tener la protección de dicha norma, por el sólo hecho de encontrarse afiliado a una entidad sindical. Con lo mencionado, rechaza la protección invocada, la nulidad del despido y la multa por práctica desleal. Para esto último, establece la Cámara que los testigos son parciales, por lo que no deben ser considerados. La Corte de Justicia de la Provincia de Catamarca confirmó la decisión de la Cámara.

En los hechos, el trabajador alegó que el 19 de abril de 2005 fue suspendido por supuestas impuntualidades y el 21 de ese mismo mes rechazó la sanción, adujo que la suspensión era una represalia por su actividad sindical y que había intimado a la empleadora para que permitiera a los trabajadores reunirse y designar delegado provisorio hasta tanto el sindicato de empleados de comercio fijara fecha de elección. El 25 de abril la empresa lo despidió con fundamento en que su conducta era agraviante. El actor sostuvo que ello encubrió un despido por motivos sindicales.

La CSJN manifestó: "En ese sentido, la apelación resulta procedente pues, si bien es cierto que las cuestiones de hecho y prueba son ajenas, como regla, a la vía del art.14 de la ley 48, corresponde hacer excepción a dicho principio cuando, como en el caso, el fallo recurrido omitió valorar prueba decisiva". La Corte apunta un poco más lejos, concretamente al acto discriminatorio, mientras que las dos instancias anteriores, se quedaron simplemente en el error conceptual de encuadre en la Ley de Asociaciones Sindicales. Dice el Tribunal Nacional, haciendo expresa referencia a la prueba y en línea con lo analizado en el precedente "Pellicori”: "Que esta Corte ha señalado cuál es el estándar de prueba aplicable cuando se discute la existencia de medidas discriminatorias en el marco de una relación de empleo dada la notoria dificultad, por la particularidad de 
estos casos, de considerar fehacientemente acreditada la discriminación. Según dicho estándar, cuando se discute si la medida obedece a un motivo discriminatorio, la existencia de dicho motivo se considerará probada si el interesado acredita de modo verosímil que la medida fue dispuesta por esa razón y, en ese caso, el demandado no prueba que responde a un móvil ajeno a toda discriminación". (...) "Una vez demostrados verosímilmente por parte del trabajador los extremos mencionados, el empleador puede todavía probar que el despido no fue discriminatorio".

La protección contra el despido discriminatorio es más amplia aún que el encuadre que pueda solicitar la parte afectada. Se aplica el principio iura novit curia y el protector del derecho debe aplicarlo; pero aún cuando no se aplicara, existe una marcada claridad en el hecho concreto que afectó los derechos del trabajador, independientemente del encuadre legal. En el caso, la protección contra el despido discriminatorio tiene sustento en el "ius cogens", descartando de plano el encuadre jurídico incorrecto o no, que pueda haber pretendido el actor. La Corte ingresa en el ámbito probatorio de la causa, donde verifica que falta valorar la prueba determinante, por lo que anula el precedente para dar lugar a otro que contemple la realidad de los hechos: "En el caso de autos el a quo, al confirmar el fallo del tribunal de alzada, ignoró el estándar probatorio descripto. Omitió valorar prueba que, a la luz de los tres aspectos de dicho estándar señalados en el considerando precedente, resultaba decisiva para una adecuada solución del pleito. Por un lado, el tribunal no consideró elementos que dan cuenta de la verosimilitud de la afirmación del actor acerca de que su desvinculación obedeció a su actividad sindical. La corte provincial soslayó la documentación de fs. 248/253 y 277/285 que acredita la existencia de una presentación concreta formulada por el demandante ante la autoridad administrativa laboral para que se convocara a elecciones de delegados de personal y de que su petición recibió acogida favorable por parte de dicha autoridad. Esto último era particularmente relevante porque torna creible que el actor estaba ejerciendo derechos sindicales protegidos por la ley 23.551 de manera regular. El a quo tampoco emitió un juicio fundado acerca de la prueba de testigos cuya ponderación tuvo relevancia concluyente en el pronunciamiento de primera instancia (fs. 290/294) para considerar acreditado que los compañeros de trabajo apoyaron los reclamos de tipo gremial promovidos por el demandante. La prueba de testigos también fue relevante en dicho pronunciamiento para establecer que la empresa conocía la gestión sindical que aquel desarrollaba. La omisión de estos elementos muestra que no está justificada adecuadamente la postura de la alzada según la cual el actor no acreditó su actividad sindical. (...) El superior tribunal local no solo prescindió de considerar elementos que hacían verosímil la postura del reclamante, sino que omitió por completo examinar si la empresa satisfizo la carga que sobre ella pesaba. En particular, el a quo no consideró si existían circunstancias que justificaran el despido con causa dispuesto por la empresa. Omitió, además, ponderar el hecho de que la primera reacción de la demandada frente al rechazo de la suspensión por parte del actor y de la comunicación formal que este efectuó en la que informaba que estaba promoviendo la elección de delegados fue el despido. Tampoco evaluó si la causal invocada por la empleadora (las supuestas impuntualidades) estaba configurada y si, en el caso de que hubiera sido asi, ello constituía injuria suficiente para justificar la desvinculación".

La protección contra toda discriminación pretendida por la Corte Suprema excede las cuestiones formales y procesales, por esto es que ingresan al análisis de la prueba verificando que no se han cumplido los recaudos necesarios para que tanto 
la Cámara interviniente, como el Tribunal Superior catamarqueño, desestimen la protección otorgada por el Juez de Primera Instancia. Se dejó sin efecto la sentencia, y se reenvió al Tribunal para una nueva solución, acorde a la opinión de la Corte.

\section{4- Conclusión}

En un giro adicional a las consideraciones ya efectivizadas por la Corte Suprema Nacional, se introduce en la valoración incorrecta de la prueba que realizan los tribunales anteriores. La CSJN termina concluyendo que el actor ha probado su calidad de activista sindical y solicita se dicte un nuevo pronunciamiento en concordancia con ello.

Como ya lo dijera en los autos "Pellicori", una vez demostrada la condición del trabajador que hace posible que sea sujeto de un acto discriminatorio por parte de la empresa, será ésta la que deba probar que el hecho que se considera afectando los derechos humanos fundamentales del trabajador (despido $\mathrm{u}$ otro) ha tenido una motivación distinta a la discriminación.

Es un nuevo avance en la protección de los trabajadores, totalmente necesaria, que tiene consonancia con los antecedentes del Máximo Tribunal en la temática, aunque los anteriores se dictaran con otra conformación. Se mantiene la línea de pensamiento. 